\title{
Eleições municipais e crise nacional: disputas eleitorais no Brasil de 2016
}

Recebido: 05.01.18 Aprovado: 03.07.18

\author{
Emerson Urizzi Cervi* \\ \& Daniela Silva Neves**
}

Resumo: O ano de 2016 foi marcado por uma eleição municipal em meio a uma das maiores crises política e econômica desde a redemocratização brasileira, no início dos anos 1980. Um dos partidos mais afetados pela crise nacional foi o Partido dos Trabalhadores, que estava no poder. Resta saber o quanto a visibilidade negativa do partido na arena nacional impactou nas disputas locais. O artigo pretende analisar os resultados das eleições de 2016 a partir de variáveis agregadas. Utiliza-se o índice de democratização para identificar padrões de democracia local e para associar o desempenho dos principais partidos a esses padrões. O objetivo é verificar que partidos conseguiram melhores resultados na atual conjuntura política. São analisados os desempenhos dos candidatos a vereador e a prefeito, nos 5.600 municípios do país.

Palavras-chave: Eleições locais. Brasil, 2016. Partidos políticos.

\section{Municipal elections and national crisis: electoral disputes in Brazil in 2016}

Abstract: The 2016 marked the impeachment of President Dilma Rousseff (PT) and one of the hardest political crises since the Brazilian redemocratization in the early 1980s. One of the parties most affected by the national crisis was the "Partido dos Trabalhadores". It remains to be seen how much the negative visibility of the party in the national arena has impacted local disputes. The article intends to analyze the results of the 2016 elections from aggregated variables. The democratization index is used to identify patterns of local democracy and to associate the performance of the major parties with these standards. The objective is to verify which parties have achieved better results in the current political conjuncture. The performance of candidates for councillor and mayor in the 5,600 municipalities in 2016 elections is analyzed.

Keywords: Local elections. Brazil, 2016. Political parties.

\section{Introdução}

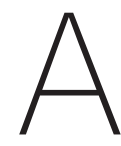

s eleições municipais brasileiras desempenham um papel importante para o sistema representativo; elas são as disputas de meio-termo que começam a organizar partidos e candidatos para as eleições regionais e nacionais que acontecem dois anos depois. Como o Congresso Nacional, as assembleias legislativas, os governos estaduais e a Presidência da República são disputadas

\author{
* Emerson Urizzi \\ Cervi é doutor em \\ ciência política, \\ professor associado \\ do Departamento de \\ Ciência Política da \\ Universidade Federal \\ do Paraná \\ (UFPR), Curitiba, \\ Paraná, Brasil. \\ Trabalho \\ desenvolvido \\ com apoio da \\ Coordenação de \\ Aperfeiçoamento \\ de Pessoal de Nível \\ Superior (Capes) \\ durante estágio \\ de pós-doutorado \\ na Universidad de \\ Salamanca. \\ Orcid: 0000-0001- \\ 8073-014X. \\ <ecervi7@gmail. \\ com>.
}
** Daniela Silva Neves é mestre em ciência política pela Universidade Federal do Paraná (UFPR) Curitiba, Paraná, Brasil, doutoranda do Programa de Pós-Graduação em Ciência Política na mesma instituição e jornalista. Orcid: 0000- 0002- 1334-0085. Orcid: 0000- 0002-1334-0085. <dneves1505@gmail. com>.


concomitantemente, a única eleição anterior para organizar as forças políticas é a disputa para prefeitos e vereadores dos 5.600 municípios brasileiros. Isso justifica o estudo de eleições municipais brasileiras como etapa de organização do sistema representativo do país. A forma como os partidos se organizam - ao considerar a possibilidade de coligações para a disputa de todos os cargos - e os resultados eleitorais - que demonstram a força dos partidos na sociedade - justificam as análises empíricas dos resultados eleitorais agregados por unidades da federação, sejam municípios ou estados. Aqui, ficaremos restritos à análise dos resultados da mais recente eleição em nível municipal.

O fato de o sistema eleitoral brasileiro ser misto, com parte dos cargos escolhidos pelo voto majoritário e parte pelo proporcional, torna necessária a distinção entre os dois nas análises empíricas dos resultados, sob pena de conclusões distantes da realidade. O objetivo aqui é utilizar um índice de democratização eleitoral para identificar possíveis variações entre municípios brasileiros a partir dos resultados de 2016 para eleições majoritárias e proporcionais. Um objetivo consequente é testar a associação entre a democratização dos municípios e os partidos bem-sucedidos nessas áreas. A questão que mobiliza o estudo é o quanto os fatores socioeconômicos conseguem explicar a democratização eleitoral nos municípios brasileiros e como isso está relacionado ao desempenho dos partidos políticos nas eleições. A hipótese é que municípios menos desenvolvidos econômica e socialmente tendem a ter menor democratização. E que quanto menor a democratização, melhor o desempenho de partidos tradicionais nessas áreas.

Para cumprir os objetivos aqui propostos, será utilizada uma adaptação do índice de democratização de Tato Vanhanen, apresentado em 2003 para comparar as democracias em 170 países do mundo. O autor considera duas dimensões fundamentais para a interpretação empírica dos níveis de democratização dos países: a participação eleitoral e a competição partidária. De uma parte, quanto maior a participação eleitoral, maior o interesse do cidadão comum e maior a possibilidade de alteração dos centros de poder político. De outra, quanto maior a competição entre os partidos, menor a concentração de poder entre poucos agentes políticos e maior a democracia. As duas dimensões fazem parte do índice de democratização eleitoral originalmente aplicado aos países por Vanhanen e que aqui serão utilizados para comparar os municípios brasileiros.

Vanhanen considera seu trabalho como uma espécie de aplicação prática dos conceitos apresentados por Robert Dahl (2005) em relação às democracias representativas. Para explicitar qual conceito de democracia eleitoral será usado aqui, parte-se de autores que medem a qualidade da democracia a partir de presença 
ou ausência de alguns elementos que consideram fundamentais, dentre os quais as eleições (Linz, 1987; Cheibub \& Przeworski 1997; Lijphart, 2000; Altman \& Pérez-Liñán, 2002; Dahl, 2005; Lijphart, 2007; Diamond, 2015). Dahl parte de um pressuposto de que para um governo responder às preferências dos cidadãos, estes devem ter oportunidades completas de formular suas preferências, de expressar suas preferências a seus concidadãos e ao governo através de ações individuais e coletivas, de ter suas preferências igualmente consideradas na conduta do governo (Dahl, 2005: 26). Isso levaria a uma conduta de maior incorporação ao sistema representativo.

Características socioeconômicas dos municípios que são indicativos de desenvolvimento social, econômico ou de localização geográfica serão usadas em cruzamentos com o índice de democratização para verificar quais características estão mais associadas à democracia eleitoral no Brasil. São esperados dois tipos de associações: positivas entre democracia e desenvolvimento socioeconômico, de uma parte, e relações negativas entre democracia eleitoral e municípios com baixo nível de desenvolvimento, de outra. No segundo momento, são comparados os desempenhos dos principais partidos políticos brasileiros com o nível de democratização municipal. O objetivo é verificar se existe um padrão de desempenho para os dois cargos em disputa ou se os partidos apresentam resultados distintos para prefeito e vereador por tipo de município. Como o Brasil dispõe de um sistema multipartidário nacional, ao todo 29 partidos elegeram prefeitos em 2016 e 30 partidos elegeram vereadores. Para racionalizar a análise, foram selecionados os dez maiores partidos por desempenho municipal, que representam $84 \%$ do total de prefeitos e 71\% dos vereadores eleitos em 2016.

A partir daqui o texto está dividido em quatro partes. Na próxima, é apresentada a recente discussão existente na literatura brasileira sobre as eleições municipais; depois é apresentada a justificação do índice de democratização e a forma como ele foi adaptado para os resultados eleitorais do Brasil; em seguida, são realizados os testes e as análises dos resultados; por fim, algumas conclusões a respeito dos "achados" empíricos sobre a democratização dos municípios e o desempenho partidário por nível de democracia eleitoral.

\section{Debate sobre eleições municipais no Brasil}

As eleições intermediárias do sistema político brasileiro incluem processos de escolha de candidatos, formação de coalizões partidárias, campanhas e resultados para prefeitos e vereadores como prévia para as disputas eleitorais regionais e para presidente da República que acontecem dois anos depois. O sistema é interli- 
gado e permite a conexão entre lideranças tanto horizontal quanto verticalmente, por estar organizado em representação por partidos nacionais. Ainda que existam dificuldades para a nacionalização dos partidos em um país de dimensões continentais como as do Brasil, as siglas nacionais permitem coexistência de interesses de lideranças locais com manutenção de um sistema multipartidário integrado. Assim, as eleições municipais brasileiras podem ser usadas como Proxy para medir a força eleitoral e a distribuição geográfica dos partidos políticos no sistema eleitoral.

No sistema federativo brasileiro, o município é o terceiro ente federado, onde prefeitos e vereadores têm mais poder institucional do que em outros países. No Brasil, os municípios têm autonomia política e fiscal, sendo responsáveis pelo patrimônio histórico e cultural além de legislarem com exclusividade em matérias de regulação e uso do solo (Brambor \& Ceneviva, 2012). Também são os principais responsáveis pela execução de políticas públicas de interesse local, em parceria com outros entes federados - estados e União - nas áreas de saúde, transporte público, assistência social e educação básica. Assim, vinculação entre as esferas municipal, estadual e federal é uma constante no sistema representativo e eleitoral. Isso dá a prefeito e a vereadores uma importância local que vai além da simples reprodução dos interesses partidários em determinado território. A autonomia administrativa, a participação como executor em programas de políticas públicas e a iniciativa de gerir recursos próprios conformam uma das possíveis explicações sobre a independência dos militantes locais em relação às estruturas nacionais dos partidos e seus programas. Com o processo de descentralização, o controle e a avaliação dos programas sociais de distribuição direta de renda - o principal deles é o "Bolsa Família" - está sob a incumbência da esfera municipal. Nas últimas décadas, os municípios também passaram a ser responsáveis pela implantação desses programas.

O interesse dos pesquisadores que desenvolvem pesquisas empíricas acerca das eleições municipais não é recente no Brasil, provavelmente porque mesmo durante a ditadura militar elas foram realizadas com voto direto para a escolha de vereadores em todos os municípios e para prefeito na maioria deles. A eleição para prefeito era de forma indireta entre 1965 e 1982 apenas para as capitais dos estado e as cidades consideradas de segurança nacional. Nesse sentido, um trabalho clássico na área é o livro de Fábio Wanderley Reis et alii (1978), Os partidos e o regime: a lógica do processo eleitoral brasileiro. Nessa publicação, um grupo de politólogos analisa os resultados eleitorais das disputas municipais de 1976 em Minas Gerais, Rio de Janeiro, São Paulo e Rio Grande do Sul, no segundo principal município de cada estado, dado que nas capitais não havia eleições diretas. São analisados os resulta- 
dos das eleições em Niterói (RJ), Caxias do Sul (RS), Juiz de Fora (MG) e Presidente Prudente (SP). Trata-se de abordagem seminal sobre a organização dos partidos e os processos de decisão de voto na escala municipal do país.

A literatura recente divide-se em duas grandes abordagens. A primeira diz respeito à estrutura partidária e ao recrutamento de candidatos por partidos, analisando as características individuais das lideranças recrutadas como candidatas e os perfis de eleitos por partido (Limongi \& Mesquista, 2008; Felisbino et alii, 2012). Há, dentro desse grupo, pesquisas sobre as dinâmicas das campanhas e a organização dos partidos na apresentação de candidatos (Moura \& Kornin, 2001; Veiga et alii, 2007). A segunda abordagem trata do tema da reeleição de prefeitos a partir de 2000.

A emenda constitucional que permite reeleição para cargos Executivos no Brasil é de 1997 e foi aplicada a primeira vez nas eleições para prefeito em 2000. Aquela eleição, além de ser a primeira a permitir reeleição de prefeitos, também foi a primeira em que houve universalização do uso de urnas eletrônicas, aumento da cota de $20 \%$ para $30 \%$ de mulheres nas listas de candidatos a vereador e mudança no cálculo do quociente eleitoral para vereador, com a exclusão dos votos brancos para o estabelecimento do quociente (Fleisher, 2000). O tema reeleição para prefeitos foi muito debatido pela literatura da área no período. Isso porque, no início, as abordagens normativo-prescritivas defendiam que os estímulos institucionais eram muito elevados para a manutenção no cargo do candidato à reeleição.

Ao debater com o trabalho de Barreto (2009) e outras pesquisas, Brambor e Ceneviva (2012) estudam a reeleição em todos os municípios brasileiros entre 2000 e 2004. Para isso, utilizam técnicas de regressão descontínua para controlar o efeito de incumbência do cargo, e encontram um efeito negativo de ser prefeito para a eleição em que disputa a manutenção no cargo. Ou seja, candidatos que disputam a prefeitura no cargo têm desvantagem em relação ao desempenho anterior, antes de eleger-se. A proporção de prefeitos que perdem a eleição gira em torno de $30 \%$ a $50 \%$ no período. Com esses resultados Brambor e Ceneviva (2012) concluem que a incumbência é um problema para os votos. A limitação é que os testes levam em conta as proporções de votos obtidas e não o sucesso ou insucesso eleitoral. Ainda assim, mostram que o risco de continuísmo em prefeituras gerado pela possibilidade de reeleição não é tão elevado como esperado. Nos termos utilizados pelos autores, prefeitos que participaram de campanha no cargo sofreram "corrosão" dos votos. Esses trabalhos empíricos permitiram relativizar os efeitos positivos para incumbents como maior exposição à mídia, facilidade para obter financiamento de campanha, disponibilidade de recursos 
governamentais para mobilizar eleitores e capacidade para dissuadir oponentes (Brambor \& Ceneviva, 2012).

A outra face desses possíveis efeitos positivos é a maior possibilidade de envolvimento em escândalos públicos e a maior limitação política local por embate com partidos de oposição, que são típicos geradores de desgaste político daqueles que estão no governo. Ao comparar as votações de candidatos a prefeito antes e depois de serem eleitos, Titiunik (2009) também encontra efeito negativo do cargo de prefeito para os candidatos à reeleição. Em média, esse efeito gira em torno de $20 \%$ de perda de votos quando se é prefeito, comparado ao desempenho anterior a ocupar o cargo.

Em abordagem distinta, Braga e Speck (2014) tratam da relação entre os partidos e o desempenho eleitoral em disputas municipais no estado de São Paulo, para o pleito de 2012. Ao aplicar regressões logísticas, eles medem a diferença do desempenho entre candidatos que disputaram eleições locais consecutivas pelo mesmo partido ou por partidos distintos. O objetivo é verificar se a fidelidade partidária apresenta algum efeito agregado sobre o desempenho eleitoral dos candidatos. Braga e Speck (2014) concluem que há uma lógica própria das disputas locais e que o sucesso eleitoral também está associado à carreira, mesmo em eleições municipais. Mais de $70 \%$ dos candidatos analisados nesse estudo mantiveram-se no mesmo partido em duas eleições consecutivas e aqueles que já foram prefeito ou deputado anteriormente têm mais chance de eleição.

Em outro trabalho que analisa o papel dos partidos nas eleições municipais, Krause et alii (2008) estudam a relação entre o surgimento de novas forças políticas e as organizações partidárias em eleições locais. A partir de uma série temporal que considera os seis principais partidos, os autores analisam o desempenho das seis principais siglas entre os anos 1990 e o início dos 2000. Uma das conclusões do trabalho é que para além das mudanças ao longo do tempo, também é possível encontrar permanências na forma de especializações regionais de algumas siglas. Por exemplo, o PSB é um partido que em eleições locais se situa principalmente na Região Nordeste do país. As análises realizadas mais adiante, nesse mesmo trabalho, reforçam, para o PSDB e PT os "achados" de Krause et alii (2008) para a especialização regional dos partidos em eleições locais.

A literatura sobre eleições municipais no Brasil é ampla e, nas últimas décadas, tem se organizado em torno das grandes questões acerca do papel dos partidos nas disputas e da influência das regras e instituições para o sucesso dos candidatos e partidos. Uma lacuna nessa literatura é o tratamento do tema de forma agregada. 
Ou os trabalhos abordam o desempenho dos partidos, seja na apresentação de candidatos, seja no sucesso eleitoral; ou tratam do tema sob o ponto de vista da reeleição dos prefeitos e vereadores. A proposta aqui é abordar o tema das eleições de forma agregada, considerando o município como unidade de análise e agregando dados de participação dos eleitores e competição dos partidos em um único índice representativo da democratização local. Além disso, buscamos explicações externas à política, em variáveis socioeconômicas, para as diferenças de democratização e de desempenho dos partidos nas disputas municipais.

\section{Materiais e métodos}

Como o objetivo aqui é utilizar variáveis agregadas a partir de resultados eleitorais de 2016, propomos, inicialmente, uma adaptação do índice de democratização (ID) proposto por Tato Vanhanen (2003) em estudo comparativo entre diferentes países. O autor considera que o nível de democratização pode ser medido empiricamente a partir do comportamento dos atores políticos nas eleições. De um lado, a elite política apresenta suas candidaturas, organizadas em partidos, que buscam o maior volume de votos possível. De outro, os eleitores, que tomam decisões distintas. A primeira é se deve ou não participar. A segunda é, uma vez participando dos processos eleitorais, em que partido ou candidato votar. Com isso, chega-se aos dois fatores que ele considera fundamentais para explicar a democratização de um país: a participação dos eleitores e a competição partidária. A partir dessas variáveis é possível identificar a distribuição de poder político em uma democracia.

O primeiro pressuposto é que quanto maior a participação eleitoral, mais forte é a democracia. Para medir a participação, o autor considera a proporção do total de votos dados em determinada eleição pela população adulta de um país. Como o objetivo era comparar países, essa foi a forma mais simples de replicar a participação em diferentes democracias. Maior proporção de participantes, mais atenção dos eleitores à democracia eleitoral e maior a possibilidade de que os centros de poder sejam deslocados dos grupos dominantes. Menor participação eleitoral, maior concentração de poder e menor a possibilidade de alterar a distribuição do poder político é o primeiro pressuposto. Logo, menos democracia tem menor participação.

O segundo pressuposto é que uma maior pluralidade de escolhas eleitorais leva a uma democracia mais consolidada. Empiricamente, a forma de medir essa pluralidade é pela participação em votos que os partidos pequenos conseguem nas eleições. Em outras palavras, quanto mais distantes estiverem os partidos vencedores dos demais partidos, maior concentração de poder em poucos partidos ou 
lideranças e isso não é um bom indicativo para a democracia. Por outro lado, se a diferença de votos entre os partidos que ganham e os que perdem é pequena, existe maior distribuição de poder político e a capacidade de "controlar" os cargos e os postos eletivos é mais dispersa.

A proposta de Vanhanen (2003) é reunir indicadores de participação e de competição em um índice de democratização para ser testado por variáveis econômicas e sociais. Em um estudo comparativo de 170 países, ele encontra correlações moderadas e fortes entre o índice de democratização e as variáveis educacionais como percentual de adultos alfabetizados e percentual de estudantes universitários e variáveis econômicas como percentual de terras com pequenos agricultores em relação ao total, percentual da economia não agrícola e crescimento do PIB per capita. Em todos os casos, as correlações são positivas com a democratização testada pelo autor.

Ao partir da teoria de Dahl (2005) de que quanto maior a participação - participação ampliada -, mais mudança potencial na composição de lideranças políticas eleitas, e de que quanto mais grupos e pessoas incluídas na competição, mais os políticos buscam apoio em outros grupos. Vanhanen defende que a concorrência (competição) e o grau de participação (inclusão) aumentariam a divisão dos recursos entre os diversos grupos. Por isso, para o autor, quanto maior a participação eleitoral, mais forte é a democracia. Da mesma forma, quanto menos concentrados os votos em determinado candidato, menor a concentração de poder. Daí surgem as dimensões (Vanhanen, 2000) e a distribuição de poder:

i. a participação percentual dos partidos menores e independentes dos votos emitidos nas eleições parlamentares ou de lugares no parlamento, ou, competição; e

ii. a proporção da população adulta que votou nas eleições, que identifica a participação.

A proposta de utilizar um índice que considere participação e competição para medir o nível de democratização eleitoral de Vanhanen (2003) é adaptada aqui para a democracia eleitoral em municípios brasileiros a partir dos resultados das eleições municipais de 2016. O princípio é o mesmo e busca criar um índice de democratização municipal para comparar os resultados entre os municípios - assim como Vanhanen (2003) fez com os países. Uma vez estabelecido o índice de democratização municipal, serão usadas as variáveis socioeconômicas dos municípios para identificar possíveis explicações para as variações de democratização local. São variáveis geográficas, como a região do país, a população do município e o pertencimento ou 
não a uma região metropolitana; econômicas, como o PIB per capita municipal e a participação da agricultura na economia local; culturais, como a taxa de analfabetismo do município.

Como o sistema eleitoral brasileiro é misto, com cargos do Poder Executivo disputados pelo sistema majoritário, e do Poder Legislativo Municipal disputado em eleições proporcionais, são gerados dois índices por município, um para eleição para prefeito e outro para vereadores. Com isso, sé possível identificar possíveis diferenças de participação e competição entre os dois tipos de eleição. A fórmula para o cálculo final do índice de democratização (ID) é exatamente a mesma que a proposta por Vanhanen:

$I D=\frac{\operatorname{compID} \times \text { partID }}{100}$

onde:

$I D$ = índice de democratização;

compID = indicador de competição;

partID = indicador de participação.

As adaptações à proposta original estão nos dois indicadores parciais. Para identificar a participação eleitoral usamos a seguinte fórmula:

partID $=\frac{\text { compar }}{\text { eleitor }} \times 100$

onde:

partID = indicador de participação;

compar = comparecimento eleitoral em número de eleitores de 2016;

eleitor $=$ total de eleitores registrados no município em 2016.

São utilizados os dados oficiais do Tribunal Superior Eleitoral (TSE) sobre a totalidade de eleitores e do comparecimento às urnas para os 5.568 municípios brasileiros que passaram por eleições municipais em 2016. Para medir a competição, usamos a seguinte fórmula:

compID $=\frac{(\text { compar }- \text { votelei })}{(\text { compar }-1)} \times 100$

onde:

compID = indicador de competição;

compar = comparecimento em número de eleitores;

votele $i=$ total de votos no partido eleito. 
O comparecimento considera todos os eleitores que votaram em candidato, partido, votaram em branco ou anularam o voto. No caso das eleições para prefeito, são considerados os votos no partido eleito para o candidato em primeiro lugar no primeiro turno de 2016. Para as eleições de vereador foram considerados os votos nominais a todos os candidatos eleitos.

A segunda parte da análise empírica visa identificar a distribuição das presenças eleitorais dos principais partidos nacionais brasileiros. Foram selecionados os dez partidos que receberam o maior número de votos - e que representam $84 \%$ dos prefeitos e $71 \%$ dos vereadores eleitos - para testar a presença eleitoral dos principais partidos pelo índice de democratização. As hipóteses que norteiam os testes realizados no trabalho são:

i. sobre a democratização: a hipótese é que municípios maiores, mais desenvolvidos econômica e socialmente, independentemente da região do país, tendem a apresentar maior competição e participação, o que os coloca em melhor posição no índice de democratização; e

ii. sobre a presença eleitoral: os partidos grandes tendem a apresentar maior presença eleitoral em municípios de diferentes perfis, até mesmo em termos regionais, o que resultará em associações distintas ao índice de democratização.

No próximo tópico são apresentados os resultados dos testes descritivos dos índices e as associações entre as variáveis externas e os índices de democratização e de presença eleitoral dos partidos.

\section{Resultados e discussão}

\section{Índices de democratização nos municípios}

Campbell (2008) diz que parte dos autores está preocupada em medir a qualidade da democracia através de indicadores publicados pelos países. Segundo o autor, em 2008 apenas três países no mundo não se autoidentificavam oficialmente como democracias, partindo dos dados da Freedom House.

Diante dessa disseminação da democracia, ou onda de democratização (Huntington, 1991; Przeworski et alii, 2000; Altman \& Pérez-Liñán, 2002), marcantemente após a queda dos regimes comunistas (Campbell, 2008; Diamond, 2015) surgiu este novo problema, que é como medir a qualidade dessas democracias. Vanha- 
nen é um dos pesquisadores preocupados com tal medição e o desenvolvimento deste conceito.

Vanhanen começou seus estudos sobre democracia nos anos 1960 e permaneceu aplicando sua proposta até 2005. Partindo do estudo de Lipset (1959), passou a se dedicar a explicar o sucesso da democracia em países pobres, como na Índia, preocupado também com a assertiva de que seria necessário um nível econômico relativamente elevado para apoiar a democracia. Neste caso, como explicar a democracia na Índia? A conclusão a que chegou (2003, referindo-se a estudo de 1963) é que a democracia sobrevivia na Índia porque, apesar da pobreza, o nível de distribuição de recursos, de poderes econômicos e intelectuais é elevado o suficiente para suportar a competitividade política. Em uma fase seguinte de seus estudos (1968-1971), partiu da hipótese básica de que poderia encontrar democracia em países subdesenvolvidos, e não apenas nos desenvolvidos, como defendia Lipset. Iniciou com um grupo de dez países e estendeu o estudo para 114 (1969-1971) chegando a cobrir 187 no mais amplo estudo (2000). Vanhanen conceitua democracia da seguinte forma:

Quero expressar por democracia um sistema político em que grupos ideológica e socialmente diferentes são legalmente habilitados a competir pelo poder político e em que os detentores de poder são eleitos pelo povo e pelos responsáveis perante o povo. O meu ponto é que devemos aplicar os mesmos critérios de democracia para todos os países, porque é razoável supor que a natureza humana é mais ou menos semelhante em todas as populações humanas (2005: 2, tradução nossa).

As eleições municipais brasileiras de 2016 ocorreram em 5.568 municípios, com mais de 144 milhões de eleitores registrados, que elegeram prefeitos, vice-prefeitos e 57 mil vereadores. Aqui, aplicaremos o mesmo princípio que Vanhanen utilizou para comparar países, aplicando-o à comparação entre municípios. De acordo com os dados oficiais do Tribunal Superior Eleitoral (TSE) de 2016, o que marca a distribuição dos municípios no Brasil é a desigualdade de tamanho. Se considerarmos o número de municípios por faixa de habitantes, dividindo-os em cinco categorias, 45\% dos municípios têm até 10 mil habitantes. Outros 44\% têm entre 10 mil e 50 mil habitantes. Apenas 11\% de municípios ficam acima de 50 mil habitantes. No entanto, a concentração de eleitores na minoria de municípios grandes é elevada. Os 2,5\% dos municípios acima de 200 mil habitantes reuniam, em 2016, 41,4\% do total de eleitores do país. Entre 10 e 200 mil habitantes estavam outros $50,8 \%$ de eleitores. E nos $45 \%$ de municípios com até 10 mil habitantes encontravam-se apenas 7,8\% dos eleitores. 
TABELA 1

ESTATÍSTICAS DESCRITIVAS DO ID PARA MUNICÍPIOS (2016)

\begin{tabular}{|c|c|c|c|c|c|c|c|}
\hline \multirow{2}{*}{ Faixa de população } & \multirow{2}{*}{ Municípios N (\%) } & \multirow{2}{*}{ Eleitores N (\%) } & \multicolumn{2}{|c|}{ IDmaj $_{(1)}$} & \multicolumn{2}{|c|}{ IDprop $_{(2)}$} & \multirow{2}{*}{ Dif. Média $a_{(1-2)}$} \\
\hline & & & Média & D.Pad. & Média & D.Pad. & \\
\hline Até 5 mil & $1.300(23,3)$ & $4.109 .643(2,8)$ & 42,13 & 7,90 & 42,18 & 9,04 & $-0,05$ \\
\hline De 5 a $10 \mathrm{mil}$ & $1.210(21,7)$ & $7.250 .812(5,0)$ & 42,07 & 7,67 & 45,54 & 8,60 & $-3,47$ \\
\hline De 10 a $50 \mathrm{mil}$ & $2.450(44,0)$ & $41.461 .426(28,8)$ & 41,86 & 8,01 & 48,69 & 8,89 & $-6,83$ \\
\hline De 50 a 200 mil & $476(8,5)$ & $31.638 .789(22,0)$ & 45,16 & 9,33 & 56,46 & 7,32 & $-11,30$ \\
\hline Acima $200 \mathrm{mil}$ & $132(2,5)$ & $59.628 .242(41,4)$ & 49,79 & 10,81 & 61,26 & 5,02 & $-11,47$ \\
\hline Média & $5.568(100)$ & 144.088 .912 & 42,44 & 8,24 & 47,45 & 9,72 & $-5,01$ \\
\hline
\end{tabular}

Importante levar em consideração essas diferenças, pois serão utilizadas como unidade de análise o município, portanto, desconsiderando as diferenças internas no número de habitantes. A Tabela 1 indica as médias e os desvios padrões para os índices de democratização para eleição majoritária e proporcional por faixa de tamanho de município. A última coluna da direita é o resultado da subtração do ID majoritário médio pelo proporcional.

As principais informações da Tabela 1 são: que a média de democratização nas eleições proporcionais $(47,45)$ é maior que a média das eleições majoritárias $(42,44)$; nos dois casos há um crescimento da democratização conforme aumenta o número de eleitores do município; a diferença cresce, passando de 11 pontos percentuais, em municípios acima de 50 mil habitantes; a heterogeneidade (medida pelo desvio padrão) do índice nas eleições majoritárias cresce conforme aumenta o número de eleitores, enquanto nas eleições proporcionais a heterogeneidade diminui nos municípios maiores. O maior número de candidatos permitido pelo sistema proporcional parece estar associado à democratização. Além disso, municípios menores tendem a ter menor índice que considera participação e competição eleitoral.

A partir daqui será testada como variável dependente o índice de democratização dos municípios pelas variáveis explicativas socioeconômicas e geográficas. As variáveis geográficas são:

i. a região do país (Norte, Nordeste, Centro-Oeste, Sudeste E Sul); e ii. se o município integra uma região metropolitana.

As variáveis sociais são: 
i. a população do município em número de habitantes em 2013 (fonte: (BGE);

ii. o percentual de famílias do município atendidas pelo programa federal de combate à miséria "Bolsa Família", em 2014 (fonte: MDS);

iii. o percentual de pessoas acima de 15 anos que não sabem ler e escrever em 2000 (fonte: IBGE); e

iv. o índice de vulnerabilidade social (IVS), proposto pelo Instituto de Pesquisa Econômica Aplicada (Ipea) para medir as estruturas públicas e privadas de atendimento social dos municípios em 2010 (fonte: Ipea).

As variáveis econômicas são:

i. o percentual da economia local de atividade agrícola (fonte: IBGE);

ii. o percentual da economia local de atividades e recursos públicos (fonte: IBGE);

iii. o número de emissoras de rádio no município (fonte: $\mathrm{MCTI}$ ); e

iv. o percentual de acessos a Internet fixa em relação à população do município (fonte: MCTI).

A Tabela 2 sumaria os resultados das regressões lineares das variáveis explicativas para democratização em eleições majoritárias e em proporcionais. Ao começar com os indicadores dos modelos, o coeficiente $r^{2}$ é nulo para a democratização majoritária $(0,035)$ e sobe para coeficiente intermediário $(0,396)$ para a proporcional. Isso significa que o conjunto de variáveis usadas aqui é mais consistente para as eleições a vereador do que para prefeito. Ainda assim, as explicações das variações para os dois modelos são estatisticamente significativas, como indicam as estatísticas $F$ da Tabela 1 . Os gráficos de distribuição dos valores preditos pelos resíduos mostram que os resíduos dos modelos não apresentam viés - ainda que o gráfico do modelo para eleições proporcionais seja mais próximo de uma nuvem de pontos do que a majoritária.

Ao considerar os resultados individuais para o índice de democratização em eleições majoritárias, quatro variáveis apresentaram coeficientes estatisticamente significativos e positivos. São elas:

i. o pertencimento a uma região metropolitana; 
TABELA 2

RESULTADOS DA REGRESSÃO LINEAR PARA ÍNDICES DE DEMOCRATIZAÇÃO

\begin{tabular}{|c|c|c|c|}
\hline \multirow{2}{*}{ Grupo } & \multirow{2}{*}{ Variável explicativa } & ID_maj & ID_prop \\
\hline & & Beta pad. (erro pad.) & Beta pad. (erro pad.) \\
\hline \multirow{2}{*}{ Geográficas } & Região país & & $-0,114^{* *}(0,110)$ \\
\hline & É reg. Metropolitana & $0,100 * *(0,351)$ & $0,080 * *(0,328)$ \\
\hline \multirow{4}{*}{ Sociais } & Número de habitantes & & \\
\hline & \% famílias Bolsa Família & & \\
\hline & $\%$ Analfabetos & $-0,204 * *(0,017)$ & $-0,584^{* *}(0,016)$ \\
\hline & IVS & $0,072 * *(1,672)$ & $0,271 * *(1,561)$ \\
\hline \multirow{4}{*}{ Econômicas } & $\%$ Receita agricultura & $-0,038 *(0,029)$ & $-0,173 * *(0,010)$ \\
\hline & $\%$. Receita pública & $0,058 *(0,022)$ & $-0,210 * *(0,021)$ \\
\hline & Núm. emissoras de rádio & $0,075 * *(0,028)$ & \\
\hline & Aces. Internet fixa & & $-0,271^{* *}(0,273)$ \\
\hline \multicolumn{2}{|c|}{ Coef. $r^{2}$} & 0,035 & 0,396 \\
\hline \multicolumn{2}{|c|}{$F($ sig.) } & $20,165(0,000)$ & $365,574(0,000)$ \\
\hline \multicolumn{2}{|c|}{ Gráfico de resíduos da regressão } & 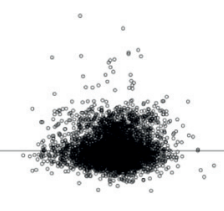 & 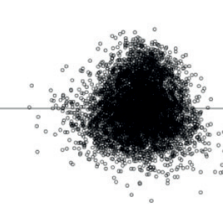 \\
\hline
\end{tabular}

${ }^{*}$ p-value $<0,100 ;{ }^{* *}$-value $<0,050 ;{ }^{* *}$ p-value $<0,010$.

Fonte: os autores.

ii. o número de emissoras de rádio no município;

iii. o índice de vulnerabilidade social (IVS); e

iv. o percentual de receita do município de origem pública.

Duas variáveis apresentaram coeficientes significativos e negativos:

i. o percentual de adultos analfabetos; e

ii. o percentual de receita do município com origem nas atividades agrícolas.

Ao comparar todos os coeficientes, o maior efeito quando controlado pelas demais variáveis é o percentual de adultos analfabetos $(-0,204)$, seguido por situar-se em uma região metropolitana $(0,100)$. Com a diferença de que o erro padrão do percentual de analfabetos é o mais baixo, ou seja, as variações entre os municípios são mais consistentes para a explicação entre o percentual de analfabetos e o índice de democratização em eleições majoritárias. 
O modelo explicativo do índice de democratização para eleições proporcionais é mais robusto que o anterior. Nele, duas variáveis apresentam coeficientes significativos positivos: o índice de vulnerabilidade social (IVS) e o pertencimento a uma região metropolitana. Outras cinco variáveis apresentam coeficientes negativos:

i. o percentual de analfabetos;

ii. o número de acessos à Internet fixa por mil habitantes;

iii. o percentual de receita pública,

iv. o percentual de receita da agricultura; e, por fim,

v. a região do país.

O maior coeficiente é o percentual de adultos analfabetos $(-0,584)$, seguido por IVS $(0,271)$ e acessos à Internet $(-0,271)$. Neste caso, também, o menor erro padrão é do percentual de adultos analfabetos.

Ao compararmos os resultados dos dois modelos, percebemos consistência da relação negativa do índice de democratização com o percentual de adultos analfabetos no município. Vale lembrar que o modelo utilizado aqui tem como unidade de análise o município e o agregado das votações para prefeito e vereador. Não podemos fazer afirmações em relação à posição individual do eleitor, nem mesmo sobre diferentes características do eleitorado, tal como nível de escolaridade ou faixa etária dentro dos municípios. Além disso, o IVS mostrou-se positivo sobre a democratização, ou seja, quanto menos acesso a bens sociais públicos nos municípios, maior a participação e a competição eleitoral.

Outra variável consistente com a democratização é o pertencimento a uma região metropolitana. Municípios metropolitanos tendem a ter democratização maior. Por fim, o percentual de receita de origem agrícola no total da economia do município também apresenta associação negativa com os dois índices de democratização. Em resumo, municípios mais agrícolas e com maior número de analfabetos tendem a ser menos democráticos. Já os municípios com a maior vulnerabilidade social e aqueles localizados em regiões metropolitanas tendem a ser mais democráticos em termos eleitorais.

Por outro lado, o percentual de receitas públicas na economia municipal apresentou efeitos com direções contrárias para os dois índices. Foi positiva para as eleições majoritárias e negativa para eleições proporcionais. O número de emissoras de rádio foi significativo e com efeito positivo para o índice em eleições majoritárias, mas 
não nas proporcionais, enquanto o número de acessos à Internet por mil habitantes apresentou efeito negativo para democratização em eleições proporcionais, mas não teve efeito estatisticamente significativo nas majoritárias. Assim como a região do país onde se realiza o pleito só explica o índice de democratização para eleições proporcionais, não para as majoritárias.

Por fim, duas variáveis sociais não apresentaram efeitos estatisticamente significativos para ambos os índices:

i. o número de habitantes; e

ii. o percentual de famílias que recebem bolsa família.

Isso significa que as diferenças apresentadas na Tabela 1 são geradas por outros fatores que não o tamanho da população. Essas diferenças são explicadas principalmente pelo percentual de adultos analfabetos, pela vulnerabilidade social e pela participação da agricultura na economia local, todas diretamente associadas ao número de habitantes.

Feitas as descrições do índice de democratização para os municípios nas eleições de 2016, no próximo tópico serão discutidos os resultados das disputas por partido e feitas as correlações com o índice de democratização (ID).

Desempenho eleitoral dos partidos

e o ID nos municípios

A partir daqui passamos a analisar o desempenho dos partidos nos municípios brasileiros, considerando os resultados apresentados nos modelos anteriores. Em 2016, nos 5.568 municípios foram eleitos prefeitos de 29 partidos e vereadores de 30 partidos. Para sumariar a apresentação dos resultados, foram selecionados os dez partidos com maior número de prefeitos e vereadores eleitos. São eles: PMDB, PSDB, PSD, PP, PSB, PDT, PR, PTB, DEM e PT. Esses dez partidos elegeram $84 \%$ dos prefeitos e $71 \%$ dos vereadores nas eleições de 2016.

De maneira geral, a Tabela 3 mostra que os partidos grandes elegeram prefeitos em municípios com baixo índice de democratização, enquanto os partidos pequenos venceram em municípios com maior índice. Se considerarmos a média geral de 42,44, o conjunto dos demais partidos, que elegeram prefeitos em 842 municípios, apresentaram uma média de 43,35 de ID. Fica acima de todas as médias individuais dos partidos grandes. Entre todos, a maior média ficou com o PT 
TABELA 3

ESTATÍSTICAS DESCRITIVAS DO DESEMPENHO DOS PARTIDOS POR ID (2016)

\begin{tabular}{|c|c|c|c|c|c|c|c|}
\hline \multirow{2}{*}{ Partido } & \multicolumn{3}{|c|}{ Prefeito $_{(1)}$} & \multicolumn{3}{|c|}{ Vereador $_{(2)}$} & \multirow{2}{*}{ Dif. $_{(1-2)}$} \\
\hline & $N$ & Média ID & D. pad. ID & $\mathrm{N}$ & Média ID & D. pad. ID & \\
\hline PMDB & 1.037 & 42,37 & 7,78 & 3.719 & 47,44 & 9,57 & $-5,07$ \\
\hline PSDB & 809 & 41,81 & 8,33 & 3.083 & 48,58 & 9,55 & $-6,77$ \\
\hline PSD & 542 & 42,48 & 8,03 & 2.759 & 47,33 & 9,86 & $-4,85$ \\
\hline PP & 498 & 42,19 & 8,19 & 2.708 & 47,21 & 9,80 & $-5,02$ \\
\hline PSB & 419 & 42,67 & 8,48 & 2.280 & 47,92 & 10,12 & $-5,25$ \\
\hline PDT & 337 & 42,05 & 8,55 & 2.286 & 47,90 & 9,76 & $-5,85$ \\
\hline$P R$ & 298 & 41,81 & 8,39 & 2.012 & 48,43 & 9,70 & $-6,62$ \\
\hline DEM & 267 & 42,42 & 8,55 & 1.911 & 48,81 & 9,39 & $-6,39$ \\
\hline PTB & 263 & 42,36 & 8,31 & 1.994 & 48,59 & 9,56 & $-6,23$ \\
\hline PT & 256 & 43,00 & 7,11 & 1.888 & 46,90 & 9,86 & $-3,90$ \\
\hline OUTROS & 842 & 43,35 & 8,68 & 4.499 & 47,44 & 9,72 & $-4,09$ \\
\hline Média geral & & 42,44 & 8,24 & & 47,45 & 9,72 & $-5,46$ \\
\hline
\end{tabular}

$(43,00)$; na outra ponta, com médias mais baixas, ficaram o PSDB e o PR, ambos com 41,81 de ID. As medidas de variação ficaram todas muito próximas da média, entre 7,11 e 8,55 de desvio padrão.

Os resultados para vereador indicam diferenças importantes. Na Tabela 3 estão registradas as médias de ID dos municípios em que o partido elegeu pelo menos um vereador. $N$ é o número de municípios em que o partido elegeu um ou mais vereadores. O N de outros é de 4.469 porque em 1.069 municípios as câmaras foram compostas por um ou alguns dos dez partidos indicados na tabela ${ }^{1}$. O PMDB foi o partido que elegeu vereadores no maior número de municípios (3.719), enquanto o PT, décimo partido na ordem decrescente de eleitos, obteve representação parlamentar em 1.888 municípios brasileiros. A primeira diferença em relação ao cargo de prefeito é que a maioria dos grandes partidos elegem vereadores em municípios com média de ID acima da média geral para o legislativo, que é de 47,45 . As maiores médias entre os grandes são do DEM, 48,81; PSDB, 48,58; e PTB, 48,59. Ficaram abaixo da média geral PT, 46,90; PP, 47,21; PSD, 47,33 e PMDB, 47,44. Se as médias dos IDs para prefeito não indicam uma tendência clara, no caso de vereador os municípios com maior índice de democratização tenderam a eleger mais vereadores de partidos da oposição ao governo federal (DEM, PSDB e PTB), enquanto municípios com IDs mais baixos tenderam a concentrar os partidos da base do então governo de Dilma Rousseff (PT).

1. Município de Nova América da Colina (PR). Todos os nove vereadores eleitos em 2016 pertenciam ao PSDB. 
Além das comparações entre partidos, os dados permitem identificar heterogeneidades dentro do partido pela diferença entre a média de ID para os dois cargos. Quanto maior a diferença, mais distintos são os municípios em que o partido elegeu prefeitos e vereadores. A diferença média geral foi de-5,46, ou seja, 5,46 pontos percentuais a menos de ID para prefeito do que para vereador. Entre os partidos grandes, as maiores diferenças ficaram com PSDB,-6,77; PR,-6,62; DEM, -6,39; PTB,-6,23 e PDT,-5,85. Apresentaram diferenças menores que a média geral os demais cinco partidos, com destaque para PT, com a menor diferença média, $-3,90$. Isso se deve ao fato de o PT ter obtido média alta de ID em municípios nos quais o partido elegeu prefeito e média baixa naqueles que elegeu pelo menos um vereador.

O Gráfico 1 torna a visualização das relações entre os partidos e a média de ID municipal mais inequívoca. No eixo horizontal está a distribuição do ID médio das eleições para prefeito; no vertical a distribuição para as eleições de vereadores. As linhas no centro da imagem dividem a mediana de cada eixo, ou seja, deixando metade dos casos para cada lado. Partidos que estão à direita da linha vertical ficaram acima da mediana de ID dos municípios nas eleições para prefeito. Os da parte esquerda ficaram abaixo. Isso vale para a linha horizontal no centro do gráfico. Partidos acima da linha tenderam a eleger vereadores em municípios com IDs mais elevados e os partidos abaixo elegeram mais vereadores em municípios de menor ID. O cruzamento das linhas cria quatro quadrantes com indicação de ID acima ou abaixo da mediana para eleições de prefeito e vereador. O Quadrante 1 reúne partidos com alto ID para vereador e baixo para prefeito; o Quadrante 2 é alto para ambos os cargos; o 3 é baixo para prefeito e vereador; e o 4 é alto para

GRÁFICO 1

ID MÉDIO POR PARTIDO NAS ELEIÇÕES PARA PREFEITO E VEREADOR (2016)

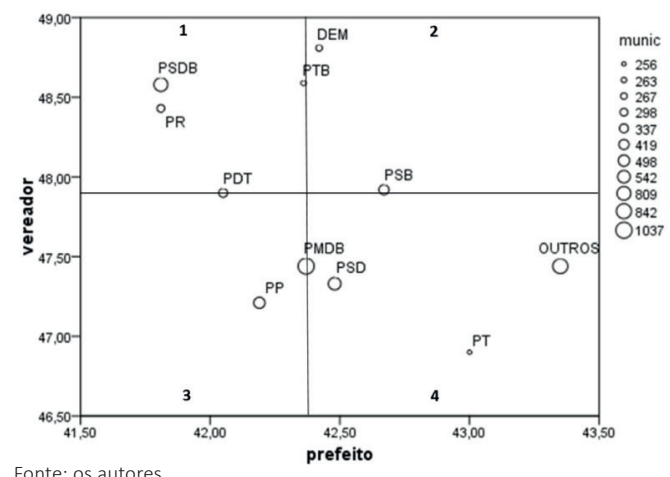


prefeito e baixo para vereador. O tamanho dos círculos de cada partido é proporcional ao número de prefeitos eleitos pelos partidos. O maior deles é o PMDB, com 1.037, seguido de todos os demais partidos, com 842 eleitos.

Ao realizar a análise por quadrante, no número 2 (que indica ID alto para as duas eleições) encontra-se apenas o DEM. No quadrante oposto, o de número 3 (área de baixo ID para os dois cargos), aparece apenas o PP, o que indica que o partido conseguiu seus melhores desempenhos para prefeito e vereador em municípios com IDs mais baixos. No número 1 (quadrante de partidos com melhor desempenho para vereador em municípios com alto ID e para prefeito em baixo ID), estão principalmente o PSDB e o PR. No número 4 (com bom desempenho para prefeito em municípios com alto ID e para vereador com baixo ID) está o conjunto dos demais partidos, o PT e o PSD.

Entre os partidos que se encontram no Quadrante 4, destacam-se o PT e o PSD, além da média dos demais partidos, indicando que, nesses casos, as médias de ID majoritária são maiores em municípios em que o partido elege prefeito e baixo ID nas eleições proporcionais. A diferença é que o número de municípios em que o PT elegeu prefeito é o menor entre os dez partidos destacados no gráfico, apenas 256 municípios. No Quadrante 1, onde se situam os partidos que conseguiram eleger prefeito em municípios abaixo da mediana de democratização e vereadores em municípios com ID alto, destacam-se o PSDB e o PR. PMDB e PTB ficam na mediana do ID majoritário, com a diferença de que o PTB está bem acima da mediana para vereador e o PMDB fica abaixo. Já na mediana das disputas a vereador estão o PDT e o PSB, com o PDT ficando abaixo da mediana de democratização nas eleições majoritárias e o PSB ficando acima. As médias dos índices de democratização por eleição e partido indicam que, de maneira geral, os partidos tendem a apresentar a mesma tendência do próprio índice, que é um comportamento distinto em termos de desempenho eleitoral por nível de democratização municipal. Não é apenas o índice que varia nos municípios, sendo maior nas disputas proporcionais do que nas majoritárias. Os partidos também apresentam comportamentos distintos nos municípios, quase que de maneira independente entre a disputa majoritária e a proporcional.

Para discutir as relações entre o desempenho dos partidos por características dos municípios, a Tabela 4 apresenta os coeficientes do teste $t$ de diferença de médias para os municípios em que o partido elegeu prefeito e aqueles onde não elegeu e para municípios onde o partido elegeu pelo menos um vereador e onde não elegeu nenhum vereador. Os coeficientes mostram se as diferenças de médias das variáveis testadas são estatisticamente significativas ou não. A tabela apresenta 
TABELA 4

COEFICIENTE DO TESTE T E NÍVEL DE SIGNIFICÂNCIA

PARA CARACTERÍSTICAS DOS MUNICÍPIOS E PARTIDOS

\begin{tabular}{|c|c|c|c|c|c|c|c|}
\hline Partido & Elei. & ID_maj. & ID_prop. & Analfab. & IVS & \%Agric. & Metrop. \\
\hline \multirow{2}{*}{ DEM } & Prefeito & & & & & & $-2,529 *$ \\
\hline & Vereador & & $7,635^{* *}$ & $-5,088 * *$ & $-4,105 * *$ & $-3,236 * *$ & \\
\hline \multirow{2}{*}{ PP } & Prefeito & & $-4,843 * *$ & $-2,934 * *$ & $-3,235^{* *}$ & $5,793 * *$ & \\
\hline & Vereador & $2,200^{*}$ & & $-6,702 * *$ & $-7,727^{* *}$ & $4,538^{* *}$ & $6,157^{* *}$ \\
\hline \multirow{2}{*}{ PSDB } & Prefeito & $-2,326 *$ & $7,799 * *$ & $-7,568^{* *}$ & $-6,767^{* *}$ & & $3,476 * *$ \\
\hline & Vereador & & $9,811^{* *}$ & $-13,932 * *$ & $-11,597^{* *}$ & $-2,096 *$ & $3,400 * *$ \\
\hline \multirow{2}{*}{ PMDB } & Prefeito & & $-2,423^{*}$ & $-4,479 * *$ & $-4,173^{* *}$ & $3,015^{* *}$ & \\
\hline & Vereador & $4,531 * *$ & & $-12,084 * *$ & $-11,819 * *$ & $3,331^{* *}$ & $4,534 * *$ \\
\hline \multirow{2}{*}{ PTB } & Prefeito & & & & $-2,142^{*}$ & $-2,069 *$ & \\
\hline & Vereador & & $6,608^{* *}$ & $-7,290 * *$ & $-6,578^{* *}$ & $-3,071^{* *}$ & $-2,709 * *$ \\
\hline \multirow{2}{*}{$P R$} & Prefeito & & $2,285^{*}$ & & & & \\
\hline & Vereador & & $5,743^{* *}$ & & $4,323 * *$ & $-2,685^{* *}$ & \\
\hline \multirow{2}{*}{ PSD } & Prefeito & & $-4,445 * *$ & $4,533 * *$ & & $-2,168 *$ & \\
\hline & Vereador & & & $6,096 * *$ & $4,830 * *$ & $-7,200 * *$ & $4,457^{* *}$ \\
\hline \multirow{2}{*}{ PT } & Prefeito & & $-2,228^{* *}$ & $3,872 * *$ & $4,012^{* *}$ & & \\
\hline & Vereador & & $-2,994 * *$ & & $2,547^{* *}$ & $2,459 * *$ & \\
\hline \multirow{2}{*}{ PDT } & Prefeito & & $-2,423^{*}$ & & & $2,776^{*}$ & \\
\hline & Vereador & & $2,924 * *$ & & $2,323^{*}$ & & \\
\hline \multirow{2}{*}{ PSB } & Prefeito & & $-2,985 * *$ & $6,793 * *$ & $4,451^{* *}$ & $-4,415^{* *}$ & \\
\hline & Vereador & & $3,063^{* *}$ & $5,165 * *$ & $3,187^{* *}$ & $-8,619 * *$ & \\
\hline
\end{tabular}

apenas os resultados que são significativos do ponto de vista estatístico. Além do teste de médias para os dois índices e democratização (majoritário e proporcional), também foram testadas as variáveis explicativas mais fortes para as variações da democratização (ver Tabela 1). Foram ainda incluídos o percentual de adultos analfabetos nos municípios, o índice de vulnerabilidade social (IVS), o percentual de renda agrícola sobre o total da economia do município e se o município pertence ou não a uma região metropolitana.

As diferenças de médias do índice de democratização para eleições majoritárias apresentam o menor número de coeficientes significativos, o que indica que é a variável mais fraca para explicar variações das presenças dos partidos nos municípios. Além disso, em dois partidos (PP e PMDB) a diferença é significativa apenas com a eleição de vereador, não com a de prefeito. O único partido que apresenta diferença de média significativa entre ID majoritária e municípios em que elegeu 
prefeito foi o PSDB, com coeficiente-2,326, o que significa que o PSDB tendeu a eleger prefeitos em municípios com ID majoritário mais baixos que os demais. Já o índice de democratização proporcional apresentou diferença de média em pelo menos um dos cargos para todos os partidos. Ele mostrou-se positivo para DEM, PSDB, PTB e PR, ou seja, esses partidos tenderam a eleger pelo menos um vereador em municípios com alto ID. Já o PP, PT, PDT e PSB apresentaram coeficientes negativos, ou seja, tenderam a estar mais presentes em municípios com ID proporcional mais baixo.

Quando analisamos os coeficientes das variáveis socioeconômicas que explicam as variações da democratização, percebemos mais claramente as principais diferenças de desempenho dos partidos por característica dos municípios. As variáveis que conseguem maior número de coeficientes significativos são percentual de "adultos analfabetos" e "índice de vulnerabilidade social" (IVS). Na sequência, vem o "percentual de renda da agricultura na economia local" e, por último, se o município pertence ou não a uma região metropolitana.

Há um padrão de coeficientes negativos para a variável "percentual de analfabetos" e o IVS com desempenho dos partidos de direita e centro-direita (DEM, PP, PSDB, PMDB e PTB), indicando que esses partidos tenderam a eleger prefeitos e vereadores em municípios com médias menores de analfabetismo e vulnerabilidade social. Já os partidos de centro-esquerda (PT, PDT e PSB) e o partido de direita PSD apresentaram coeficientes positivos com as duas variáveis, ou seja, com desempenho melhor em municípios com maior percentual de analfabetos e o maior índice de vulnerabilidade.

No caso da variável que indica o tipo de economia local, o percentual de renda da agricultura, os resultados não permitem dividir os partidos por ideologia. DEM, PSDB, PTB, PR, PSD e PSB apresentam coeficientes negativos, ou seja, tiveram resultados eleitorais em municípios onde a participação da agricultura na economia local apresenta médias mais baixas. Já o PP, o PMDB, o PT e o PDT tiveram diferenças de médias positivas, com melhores desempenhos em municípios com maior presença da economia primária na economia local. Quanto ao desempenho em municípios que pertencem a regiões metropolitanas, percebe-se que nos casos do PP, do PMDB e do PSD os coeficientes são positivos apenas para a eleição a vereador. Para o PSDB os coeficientes são positivos para os dois cargos. Para o DEM é negativo para prefeito e para o PTB, negativo para vereador. 


\section{Conclusões}

Antes das notas conclusivas, reforçamos que existem dois objetivos específicos no artigo, apresentados de forma sequencial:

i. descrever os índices de democratização eleitoral nas eleições municipais de 2016, com controles de variáveis sociais;

ii. a partir dos "achados" no objetivo anterior, testar o quanto eles conseguem explicar o desempenho de partidos políticos nos municípios brasileiros.

Como primeira conclusão, é preciso destacar a necessária diferenciação entre sistemas majoritários e proporcionais em análises empíricas sobre eleições no Brasil. O sistema eleitoral brasileiro é misto e essa característica precisa ser respeitada, sob pena de produzir resultados que não representam toda a diversidade típica de um sistema misto. No caso em análise, as disputas municipais para vereador mostraram-se com índice de democratização (ID) mais alto que o das eleições majoritárias. Há mais participação e competição em eleições por lista do que naquelas em que um único candidato representa um partido.

A segunda conclusão é que as eleições municipais brasileiras - como eleições de meio termo - são organizadoras das disputas nacionais que acontecem dois anos depois. Assim, a adaptação de um índice de democratização municipal pode servir como Proxy para o desempenho de partidos em eleições regionais ou nacionais. Nesse sentido, a adaptação do índice de democratização de Vanhagen para as eleições de 2016 mostrou-se bastante útil por permitir uma série de classificações dos municípios. A primeira delas, já apontada aqui, é que há mais democratização em disputas proporcionais que em majoritárias. A segunda é que algumas variáveis socioeconômicas e geográficas apresentam associações consistentes com democratização eleitoral, outras não.

Em terceiro lugar, a diferença em ID por tipo de eleição é reproduzida no desempenho dos principais partidos. Nas eleições para prefeito, os partidos grandes conseguem melhor desempenho em municípios de ID mais baixo. Já nas eleições para vereador, o desempenho positivo dos partidos grandes tende a estar mais associado a ID mais alto. Isso é ainda mais forte no caso de partidos grandes de direita e centro-direita, notadamente PSDB, DEM e PTB.

A respeito das relações entre partidos e características dos municípios, em primeiro lugar, o índice de democratização não se mostrou com fortes associações com 
os partidos grandes. Já o índice para eleições proporcionais, sim. E isso vale para os dois cargos, prefeito e vereador.

A conclusão é que alguns partidos logram melhor desempenho em situações de maior competição e participação, enquanto outros não. Destacam-se nesse ponto, com diferenças de médias positivas para ID em eleições proporcionais, O PSDB e o PR; e diferença de médias negativa o PT. Ou seja, os dois primeiros obtiveram melhores desempenhos em municípios com ID alto, enquanto o último em municípios de baixa democratização. Sobre as médias das variáveis socioeconômicas, as principais conclusões são que em 2016 partidos de direita e de centro-direita conseguiram melhores desempenhos em municípios com alta democratização. Já os partidos de esquerda ou que faziam parte do governo do PT tiveram melhores resultados em municípios com médias de variáveis socioeconômicas baixas. As variáveis mais explicativas são o percentual de adultos analfabetos e o índice de vulnerabilidade social (IVS). Sobre a presença em municípios que pertencem a regiões metropolitanas, o PSDB apresentou as associações com médias mais consistentes. É o partido que obteve melhor desempenho em regiões metropolitanas tanto para prefeito como para vereador. Todos os demais apresentaram resultados inconsistentes com essa variável.

Tratamos aqui apenas de uma eleição, a municipal de 2016. É preciso uma série histórica para identificar possíveis variações no tempo, o que não nos permitimos fazer aqui. De qualquer maneira, em 2016 a imagem comum de que os partidos de esquerda tendem a ter melhor desempenho em municípios com índices de desenvolvimento mais elevados não se comprovou. Ao contrário, partidos de direita se destacaram em municípios com menor analfabetismo, enquanto os governistas e de esquerda tiveram melhores desempenhos em municípios com economia baseada na agricultura e percentuais de analfabetismo mais elevados. Também é possível que isso tenha relação com o contexto em que a eleição de 2016 se desenvolveu, em meio a um ambiente muito centrado no tema da corrupção de governos que envolvem partidos de esquerda.

\section{Referências}

ALTMAN, D.; PÉREZ-LIÑÁN, A. Assessing the quality of democracy: freedom, competitiveness and participation in eighteen Latin American countries. Democratization, v. 9, n. 2, p. 85-100, 2002.

BARRETO, Alvaro A. de B. Reeleição para executivo municipal no Brasil (2000 a 2008). Revista Debates, v. 3 n. 2, p. 97-115, Porto Alegre, 2009. 
BRAGA, Maria do S. S.; SPECK, Bruno. Organização partidária e carreiras políticas no nível local. XII Encontro Brazilian Studies Association (Brasa). Londres, 2014.

BRAMBOR, Thomas; CENEVIVA, Ricardo. Reeleição e continuísmo nos municípios brasileiros. Revista Novos Estudos Cebrap, n. 93, p. 9-21, 2012.

CAMPBELL, David F. J. The basic concept for the democracy ranking of the quality of democracy. Vienna: Democracy Ranking, 2008.

CHEIBUB, José A.; PRZEWORSKI, Adam. Democracia, eleições e responsabilidade política. Revista Brasileira de Ciências Sociais, v. 12, n. 35, Fev. 1997.

DAHL, Robert. Poliarquia: participação e oposição. São Paulo: Editora Universidade de São Paulo, 2005.

DIAMOND, Larry. O espírito da democracia: a luta pela construção de sociedades livres em todo o mundo. Curitiba: Instituto Atuação, 2015.

FELISBINO, Riberti de Almeida et alii. Somente um deve vencer: as bases de recrutamento dos candidatos à prefeitura das capitais brasileiras em 2008. Revista Sociologia e Política, v. 20, n. 41, p. 219-234, 2012.

FLEISHER, David. As eleições municipais no Brasil: uma análise comparativa (19822000). Revista Opinião Pública, n. 1, p. 80-105, Campinas, 2002.

HUNTINGTON, Samuel P. The third wave: democratizacion in the late twentieth century. Norman (OK): University Of Oklahoma Press, 1991.

KRAUSE, Silvana et alii. As eleições municipais e a emergência de novas forças políticas. Bogotá: Alacip, 2008.

LIJPHART, Arend. Thinking about democracy: power sharing and majority rule in theory and practice. London; New York: Routledge, 2007.

- Modelos de democracia - formas de gobierno y resultados em treinta y seis países. Barcelona: Ariel, 2000.

LIMONGI, Fernando; MESQUISA, Lara. Estratégia partidária e preferência dos eleitores: as eleições municipais em São Paulo entre 1985 e 2004. Revista Novos Estudos Cebrap, n. 81, p. 49-67, 2008.

LINZ, Juan J. La quiebra de las democracias. Madrid: Alianza Editorial, 1987.

LIPSET, Seymour M. Some social requisities of democracy: economic development and political legitimacy. American Political Science Review, v. 53 n. 1, p. 69-105, 1959. 
MOURA, Rosa; KORNIN, Thaís. (Des)construindo o discurso eleitoral: o primeiro turno das eleições municipais majoritárias em Curitiba no ano 2000. Revista de Sociologia e Política, n. 16, p. 67-95, 2001.

PRZEWORSKI, A.; Alvarez, M.; CHEIBUB, J.; LIMONGI, F. Democracy and development: political institutions and material well-being in the world, 1950-1990. Cambridge (UK): Cambridge University Press, 2000.

REIS, Fábio W. et alii. Os partidos e o regime: a lógica do processo eleitoral brasileiro. Rio de Janeiro: Centro Edelstein de Pesquisas Sociais, 1978.

TITIUNIK, Rocío. Incumbency advantage in Brazil: evidence from municipal mayor elections. Berkley university: paper, 2009.

VANHANEN, Tatu. Democratization: a comparative analysis of 170 countries. London: Routledge, 2003.

- A new dataset for measuring democracy, 1810-1998. Journal of Peace Research, v. 37, n. 2, p. 251-265, 2000.

VEIGA, Luciana Fernandes et alii. As estratégias de retórica na disputa pela Prefeitura de São Paulo em 2004: PT, mandatário, versus PSDB, desafiante. Opinião Pública, v. 13, n. 1, p. 51-73, 2007. 
